\title{
Book Review - The Impact of E-Learning Programs on the Internationalization of the University
}

Authors: Amirault, Ray J., \& Visser, Yusra L. (2010). The Impact of E-Learning Programs on the Internationalization of the University. New York: Nova Science Publishers. ISBN: 978-1-61728-317-8

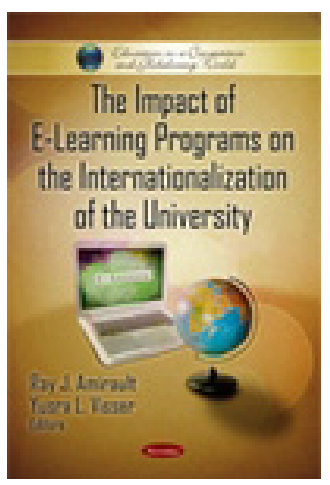

Reviewer: Nataly Tcherepashenets, State University of New York, USA

While I was preparing the grant application for a project that involves international collaboration in online learning and teaching, I came across a book titled The Impact of Elearning Programs on the Internationalization of the University by Ray J. Amarault and Yusra L. Visser, both scholars in the field of educational technology and research at Florida Atlantic University. This insightful book includes seven engaging chapters which combine the historical, educational, and technological dimensions of internationalization to address the potential impact of web-based e-learning.

In the introduction, the authors contend that internationalization has been a top priority for higher education from the time of the university's inception, and it is one of the key mechanisms responsible for the institution's enduring achievements. In the first chapter, Amarault and Visser introduce university internationalization as a subject of research. In the second, "Defining 'Internationalization," they note a correlation between the growing interest in internationalization as an educational process and the development of webbased e-learning, both of which have a codependent relationship with globalization. After providing some history about internationalization, whose success has been primarily driven by the mobility of faculty and students, the authors analyze the impact of technology, or the "technology revolution" (p. 17), on the recent internationalization efforts in higher education.

As the researchers aptly demonstrate in chapters $3-5$, the emergence of web-based e-learning in the late twentieth century created the potential for internationalization within the university. However, it is no small task to take full advantage of this possibility. A central question emerges: 
Has this historic shift towards web-based e-learning actually increased internationalization within the university by allowing greater cross-national student and faculty participation, or has it rather decreased internationalization by eliminating the traditional requirement for face-to-face meetings within classrooms, where the effects of direct human interaction might be most keenly felt? (p. vii-viii)

There is no simple answer to this question. In chapters 6 and 7, the authors analyze seven factors present in web-based e-learning which, in their opinion, may have a positive impact on internationalization within the university. These are (1) faculty role, (2) student role, (3) student and faculty migration, (4) community and cultural context, (5) availability of knowledge and information, (6) educational access, and (7) instructional strategies. Amarault and Visser suggest that in order to enhance internationalization in the online environment, faculty members should be open to taking on the role of facilitators. In this role, they must possess strong writing skills and be willing to assist students of various ethnic, cultural, and linguistic backgrounds to develop cognitive and metacognitive skills. Faculty participation in online course design acquires major importance, along with subject matter expertise. The collaborative engagement of students can be a very positive factor particularly when there is an opportunity for interaction between individuals from different cultural backgrounds, which may contribute to internationalization. Amarault and Visser correctly observe that in the best of cases, these "differences can be viewed as strengths on which to capitalize in the online environment” (p. 27).

Although web-based e-learning reduces faculty and student migration, the approach can have a positive impact on internationalization. This can be achieved, for example, with online communication between people from different countries. Many interdisciplinary and interinstitutional collaborations can be facilitated by the affordances of advanced communication technology. The success of this process is also determined by the learning management systems (LMS) in place, which shape both community and cultural contexts and can either enhance or impede internationalization. And, as the authors point out, there is a continuing need to develop content that encompasses elements from a wide range of cultural, geographical, and political backgrounds. The fact that this knowledge and information is available through open access both in the original language and in translation contributes positively to internationalization.

Furthermore, in contrast to the traditional migration pattern, distance education can potentially be accessible to a wide variety of people because there is no need to relocate. Although the digital divide continues to exist (there are still billions of people around the globe without Internet access, as statistics illustrate), it is shrinking. For example, the number of Internet users worldwide in 2010 grew 444.8\% in comparison to percentages from 2000 (see http://www.internetworldstats.com/). Amarault and Visser note another problem, which is Internet penetration. This varies significantly in some of the most heterogeneous regions 
of the world. According to Internet World Statistics, as of June 2010, penetration rates are 77.4\% in North America, 58.4\% in Europe, and 10.9\% in Africa. Despite these limitations, the increased access to the Internet that many populations have may support internationalization for the university.

Instructional strategies play a major role in promoting internationalization efforts. Amarault and Visser consider group-based activities, integrating of materials from a variety of cultural traditions and geographical regions, and interviews to be the most successful instructional strategies for enhancing internationalization. They mention specific technologies that support internationalization in virtually any academic subject, including online translation tools, Internet connection speeds capable of supporting real-time audiovisual communication, the emergence of cloud computing, and social networking.

In the final chapter, titled "Discussion," Amarault and Visser suggest that understanding the seven factors, which they described earlier, in light of Knight's scheme of internationalization (1999) can be instrumental to strategic planning for reaching internationalization goals. According to the authors, the impact of e-learning on students and faculty migration are aligned most closely with the activity approach of Knight's internationalization scheme, which focuses on curriculum, academic exchange, and international students. They see the modification of the roles of faculty and students as part of the competency approach, with its emphasis on knowledge, skills, and attitude development. The integration of digitally archived intellectual content from diverse regions into web-based learning links fits the ethos approach, which emphasizes culture or climate development that supports internationalization. Finally, Amarault and Visser view instructional strategies as being aligned with Knight's process approach, which stresses the integration of international elements into teaching, research, and service. In the same vein, one may notice strong connections between the seven factors and Knight's approaches to internationalization. These relationships should be taken into consideration when strategies for internationalization are developed.

The authors then move from analyzing the potential impact of web-based e-learning to the discussion of real situations and outstanding questions. They notice, for example, that web-based e-learning might filter out certain aspects of internationalization because the individuals using the required technology are working in a single language, and the textual communication does not transmit many of the features inherent in cross-cultural intercourse, such as accents, mannerisms, styles of verbal communication, and study and learning patterns. This can be addressed, according to the authors, by integrating audio and video streaming, a real-time audio and video connection between individuals in an online classroom. As this technology becomes more widely available, aspects of intercultural discourse between students and faculty will be improved. The wider implementation of this technology will increase the level of university internationalization through e-learning. It requires a careful and systematic approach that must be factored into long-term strategies.

Although distance learning was ranked at the bottom of the list among internationalization policies and practices by the International Association of Universities in 2006, it was placed 
among the key areas for new development within internationalization in a 2003 IAU global report. As Amarault and Visser correctly conclude, the lack of consensus over this period of time exemplifies the uncertainty many feel about the role of distance learning in internationalization processes. The authors suggest that web-based e-learning has the potential to increase internationalization. This can be achieved, for example, through the purposeful implementation of strategic policies which count internationalization through distance learning among the major institutional goals of the university.

In conclusion, Amarault and Visser view web-based e-learning as instrumental for achieving internationalization outcomes if a deliberate, systematic, and proactive approach is taken to reach that goal. A clear statement of internationalization goals, an understanding of the technology affordances, and the implementation of targeted instructional strategies are the necessary steps in order to ensure a true internationalization experience in the twentyfirst century university's virtual world. This interdisciplinary book offers an innovative look at internationalization and the role of distance learning in this process by incorporating historical, educational, and technological perspectives. It will be of interest to a broad audience of researchers and practitioners in online learning, particularly those who are planning to contribute to their institution's internationalization efforts.

\section{Athabasca University $\mathbf{Z}$}

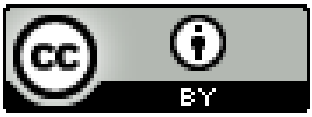

